Research Article

\title{
Design of Smart Classroom System Based on Internet of Things Technology and Smart Classroom
}

\author{
Mingbao Zhang (iD) and Xiang Li \\ School of Digital Arts and Design, Dalian Neusoft University of Information, Dalian 116023, Liaoning, China \\ Correspondence should be addressed to Mingbao Zhang; zhangmingbao@neusoft.edu.cn
}

Received 18 May 2021; Revised 18 June 2021; Accepted 28 June 2021; Published 8 July 2021

Academic Editor: Sang-Bing Tsai

Copyright (C) 2021 Mingbao Zhang and Xiang Li. This is an open access article distributed under the Creative Commons Attribution License, which permits unrestricted use, distribution, and reproduction in any medium, provided the original work is properly cited.

\begin{abstract}
Smart classroom teaching is one of the new teaching methods. With the support of technology, teaching is carried out with the help of smart teaching tools to enhance teacher-student communication, enhance students' learning autonomy, and provide new ideas for the realization of students' deep learning. How to promote the overall intelligence of the teaching environment so that the teaching equipment can be used more efficiently and managed more effectively has become the main concern of schools. This article mainly studies the smart classroom system based on the Internet of Things technology and smart classroom. For temperature detection, we mainly use the DS18B20 chip to detect the temperature in the classroom. For the light intensity of the classroom, we use a photoresistor to collect the light data, and after amplification by the amplifier, the A/D sampling process of the single-chip microcomputer is used to obtain the light intensity, combined with the clock module to distinguish the influence of the classroom light. The data collection adopts the method of directly observing the source data, and the data format has not undergone secondary conversion, which ensures the accuracy of the source data. This test uses the USR-TCP232 network debugging assistant to debug the data collection. To optimize the safety and reliability of the system, dual-computer backup switching is adopted on the hardware, and process monitoring and management strategies are adopted on the software. At the same time, the amount of data interaction in the smart classroom is relatively large, so it is necessary to build a highly available cluster server, so that the system not only has a certain degree of stability, but also can quickly respond to users' access requests. We can calculate that the average transmission time is about $10 \mathrm{~ms}$, and $99.9 \%$ of the data transmission delay is less than $30 \mathrm{~ms}$. The results show that the Internet of Things and smart classroom provide great convenience for future smart campus construction, daily teaching, and campus management and can also provide reference for the construction of smart classrooms in other universities.
\end{abstract}

\section{Introduction}

The continuous development of new media technology promotes the development of modern education technology and at the same time puts forward higher requirements for modern education technology workers. The continuous updating of educational technology, coupled with the improvement of the functionality and operability of multimedia classrooms, has created favorable conditions for the application of modern educational technology in colleges and universities. The use of multimedia equipment to develop and serve modern teaching has become a common phenomenon and then developed into a new teaching mode.
Based on the concepts of smart equipment management, safety management, and energy-saving management in the classroom, this paper designs and develops an IoT cloud platform for smart classrooms and realizes real-time management of classroom environment information, combined with the development of smart campus.

With the development of information technology and the wave of intelligent technology, colleges and universities are exploring new teaching models to meet the needs and development of education. Through thinking and improving teaching, students' subjective initiatives can be mobilized and their creativity cultivated. The Internet of Things technology is developing rapidly. The use of Internet of 
Things technology to build smart classrooms is helpful for information sharing and analysis and has a significant impact on the way of learning knowledge. Students majoring in the Internet of Things, computer, and other related majors can use the platform to learn wireless sensing technology and embedded development technology and can also use the provided interface to carry out the secondary development of the project.

The environment created by the smart classroom stimulates students' interest in learning, thereby improving the quality of education and teaching. Li believes that as the Ministry of Education vigorously promotes the construction of smart campuses, the development concept of smart campuses will have broad application prospects. However, colleges and universities are still at the stage of digital campuses, and there are still many problems. He designed and realized a complete intelligent campus management system by analyzing the design principles and design goals of the system. His system is mainly divided into face recognition terminal hardware based on the Internet of Things and smart campus software system. Although the user satisfaction of the system he studied is relatively high, there are still certain shortcomings [1]. Kim believes that the degree of student participation refers to the degree to which students are immersed in learning when receiving education in the classroom. He proposed an environmental intelligence algorithm for smart classrooms. The algorithm provided information to teachers by measuring student participation in real time. He proposed an algorithm for evaluating student participation by measuring thermal infrared images to evaluate students' mental state. He proposed a measurement model that uses thermal infrared imaging to characterize student participation. The color of the teacher's mobile application will change in real time according to the immersion level of the students in the classroom. Although the algorithm he proposed is innovative, it lacks algorithm simulation [2]. Tissenbaum and Slotta believe that although K-12 media has had a significant impact on many other aspects of life, people's classroom environment has not yet incorporated ubiquitous computing, augmented reality, and other emerging technologies, even touch screens. He has carried out a series of designbased research projects to investigate the smart classroom infrastructure, which provides support for students and teachers in a new form of collaboration and inquiry, including the substantial role of large projection displays and small touch surfaces, as well as the dependence of the student's physical location in the room. His design includes (1) the role of a large-screen display to transmit aggregate information and environmental information, (2) real-time communication between students, (3) application of intelligent software agents to formulate real-time teaching logic, (4) support cross-context learning, and (5) investigate the coordination of roles, materials, and environment. Although his research has a certain role in promoting the development of smart classrooms, it lacks specific experimental data [3]. Lin believes that, in recent years, many organizations have announced the importance of software development to the country, society, and individuals. In the process of software development, various unpredictable problems are often encountered, especially when developing large and complex software. To reduce the possibility of these problems, it is essential for students to apply software engineering techniques to scientifically define the standards, models, and processes required in the software development process. His goal is to apply an innovative teaching method, called flipped classroom, to implement a learner-centered learning environment in software engineering courses. In addition, he also developed an intelligent learning diagnosis system to support the teaching of this course. He conducted experiments on a software engineering course at a university in Taiwan to explore the effectiveness of the proposed method. The experimental group adopts the flipped classroom teaching method, and the control group adopts the traditional classroom teaching method. Although his research is more accurate, it is not innovative enough [4].

Through the Internet of Things application platform for teachers and students to build a learning experience platform with strong credibility, teachers and student users can integrate into all aspects of the Internet of Things application platform through actual operation and management, which facilitates the high-speed flow and sharing of information resources. To make full use of the Internet of Things application technology to enhance the information management of the university classrooms, based on the professional characteristics to promote the integration of theory and application practice of diversified universities, through the Internet of Things application platform to provide teachers and students with a strong credibility of learning experience, teachers and students can integrate into all aspects of the Internet of Things application platform through the actual operation and management.

\section{Smart Classroom System Design}

2.1. Internet of Things. With the rapid development of the Internet of Things, a large amount of unstructured data will be generated. These data are growing exponentially. The data are complex and polymorphic, and there is no obvious correlation between them. However, the traditional data acquisition, analysis, storage, and processing technologies can not meet the needs of the rapid development of society $[5,6]$. Therefore, if we can focus on the following key technologies in data processing of the Internet of Things according to the characteristics of data, massive data storage, data fusion, data query, search and mining, intelligent decision making, etc., it will play a technical support and promotion role in information construction, smart city, industrial manufacturing, smart agriculture, commerce, finance, transportation, and other fields $[7,8]$.

Assuming that, in the regression of the function curve, the weight coefficient $A$, the standard deviation $S$, the mobile application behavior variable $x$, and the linear change variable $y$ ensure a high degree of fit between the function curve and the sample point data, it is necessary to establish an alternative relationship expression between $x$ and $y$ based on the regression equation formula. The calculated residual SS can be used to determine whether the fitting is a composite 
data mining analysis requirement, and the expression is as follows [9]:

$$
\begin{aligned}
& A=\sqrt{1-\frac{\sum_{i=1}^{n}\left(x_{i}-y_{i}\right)}{\sum_{i=1}^{n}\left(y_{i}-y_{i-1}\right)}}, \\
& S=\sqrt{\frac{\sum_{i=1}^{n}\left(y_{i}-y_{i-1}\right)}{n-\sqrt{n}}}, \\
& \mathrm{SS}=\sqrt{\frac{\sum_{i=1}^{n}\left|A_{i}-S_{i}\right|}{n-\sqrt{n}} .}
\end{aligned}
$$

The relationship between the conversion delay of the curve regression sampling point and the perception accuracy is as follows:

$$
D_{T}=\sum_{i=1}^{n}|d|^{2} \delta(\omega-\oplus) .
$$

Among them, $D_{T}$ represents the conversion delay and $d$ represents the perception accuracy [10].

The errors of linear data mining are as follows:

$$
\operatorname{dif}=\frac{\sum_{i, j}^{n, m} x_{i, j} P\left(x_{i-1, j-1}\right)}{\sum_{i, j}^{n, m} x_{i, j}} .
$$

Among them, $i$ represents the user scale, $j$ represents the number of data mining polls, and the function $P$ is used for curve fitting [11].

The similarity between the user demand conclusion of linear data mining and the actual demand is as follows:

$$
\mathrm{SL}=\frac{\sum_{i, j}^{n, m} x_{i, j} P\left(x_{i, j}\right)-\mathrm{dif}}{\sum_{i, j}^{n, m} \sqrt{P\left(x_{i, j}\right)}} .
$$

The characteristics of the Internet of Things technology are to give objects to perceive the environment and to communicate with each other and have simple intelligence, so for the architecture design, the Internet of Things needs to support the above three main features. Generally speaking, the technical architecture of the intelligent Internet of Things can be divided into three levels. We can call it the control layer or perception layer, the transmission layer or network layer, and the application layer or service layer $[12,13]$. After the IoT terminal device perceives the surrounding environment data, these data need to be transmitted. Therefore, the support of the network layer is required. Through the connection of the network layer, objects can be connected in series to form a mesh structure. In addition to transmission, the confidentiality and correctness of data transmission must be ensured, while stability and continuity are required. The higher-level requirement is to occupy less bandwidth and the transmission process needs to occupy less energy consumption $[14,15]$.

Zigbee wireless network channel distribution is shown in Table 1. Different types of network can be used to transmit different types of data to achieve the optimal allocation of network resources and the perfect integration of sensor network and current network and to realize fast, stable, accurate, safe, and reliable transmission of data. On the terminal, various functional requirements can be realized according to data characteristics and user needs, which can be realized through application design and development [16].

2.2. Smart Classroom System. The system structure of the smart classroom system is shown in Figure 1. Pad mobile platform allows users to register and $\log$ in and realize the collection and upload of basic face information; through receiving the instructions from $\mathrm{PC}$ workstation, the collection and preprocessing of face attendance information are completed; the submission of face attendance information is completed, the online examination, teaching evaluation, electronic whiteboard display, and other functions are realized, and the results of teaching evaluation information and performance information can be queried in real time [17].

The equipment control system in the classroom uses PID control related technology to set the target temperature value, realize automatic temperature control, and adjust the set value of stable operation in the target area. The relationship between the three PID algorithms is [18]

$$
\mathrm{PID}_{\text {out }}=P_{\text {out }}+I_{\text {out }}+D_{\text {out }} \text {. }
$$

In the formula, $\mathrm{PID}_{\text {out }}$ represents the total output value, $P_{\text {out }}$ represents the current deviation value, $I_{\text {out }}$ represents the historical deviation value, and $D_{\text {out }}$ represents the latest deviation value [19].

Suppose that $N$ sensors are used to perform feature detection with a certain performance index of the target object independently of each other, and the obtained data is sorted in ascending order to obtain a set of detection sequences $T_{1}, T_{2}, \ldots, T_{n-1}, T_{n}$, where $T_{1}$ is the lower limit of the detection sequence, and $T_{n}$ is the upper limit of the detection sequence [20]. Define the median $T_{M}$ as

$$
T_{M}=\frac{T_{(n / 2)}+T_{(n / 2)+1}}{2} \text {. }
$$

According to the extreme value theory of multivariate functions, the minimum condition of the total mean square error $\sigma^{2}$ is obtained. The weight corresponding to each sensor is $W_{i}(i=1,2, \ldots, n)$. When the variance is smaller, the corresponding weight evaluation factor is larger [21]. The weighting factor $W_{i}$ of each sensor corresponding to the minimum total mean square error $\sigma_{\min }^{2}$ is [22]

$$
\begin{gathered}
\sigma_{\min }^{2}=\frac{1}{\sum_{i=1}^{n}\left(1 / \sigma_{i}^{2}\right)}, \\
W_{i}=\frac{1}{\sigma_{i}^{2} \sum_{k=1}^{n}\left(1 / \sigma_{k}^{2}\right)}(i=1,2, \ldots, n) .
\end{gathered}
$$

2.3. Smart Classroom. Any education ecosystem is inseparable from the social environment. The material flow, energy flow, and information flow in the education ecosystem will 
TABLE 1: Zigbee wireless network channel distribution.

\begin{tabular}{lccccc}
\hline $\begin{array}{l}\text { Number of frequency } \\
\text { bands }\end{array}$ & $\begin{array}{c}\text { Channel frequency } \\
\text { spacing }\end{array}$ & $\begin{array}{c}\text { Transfer speed } \\
(\mathrm{kbps})\end{array}$ & $\begin{array}{c}\text { Modulation } \\
\text { mode }\end{array}$ & $\begin{array}{c}\text { Maximum } \\
\text { frequency }\end{array}$ & $\begin{array}{c}\text { Minimum } \\
\text { frequency }\end{array}$ \\
\hline 1 & 0 & 20 & B0SK & $868.2 \mathrm{MHz}$ & $868 \mathrm{MHz}$ \\
10 & 2 & 40 & HPSK & $928 \mathrm{MHz}$ & $902 \mathrm{MHz}$ \\
16 & 5 & 250 & QPSK & $2483.5 \mathrm{MHz}$ & $2400 \mathrm{MHz}$ \\
\hline
\end{tabular}

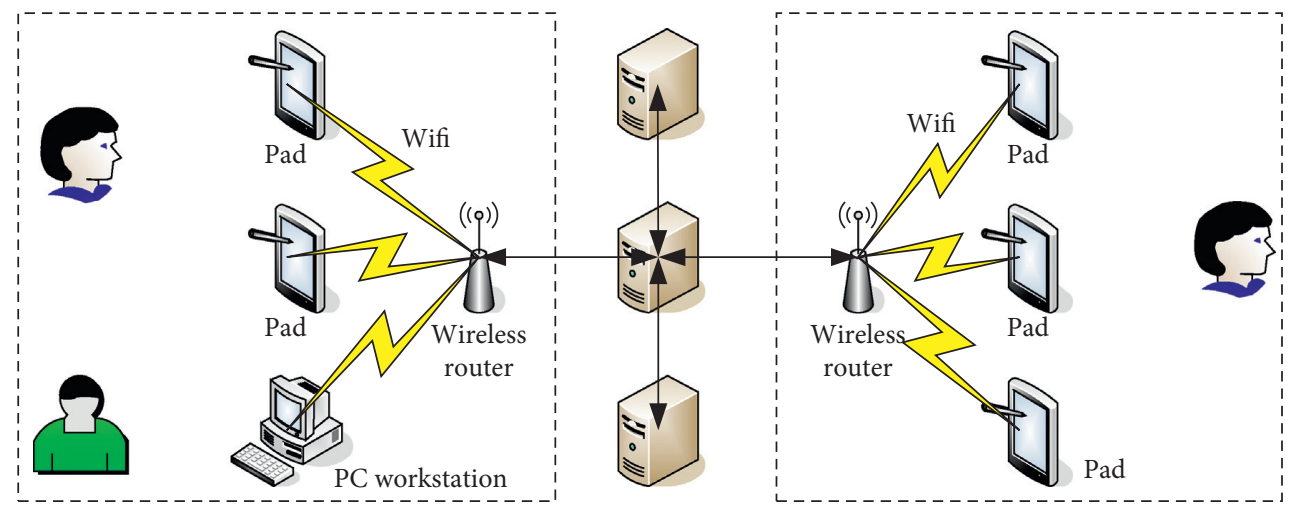

FIgURE 1: The system structure of the smart classroom system.

eventually be transformed into social benefits and serve the society. Whether it is the cultivation of talent or technological inventions and creations, they will eventually appear in the society. The society has been developed and progressed, and the economic benefits produced are invested in education to promote the redevelopment of education and form a virtuous circle of sustainable development [23]. Education bears the responsibility of historical and cultural heritage. Any education ecosystem not only presents the function of serving people and society, but also contains more or less cultural details. For example, in a university, cultural heritage is more important than teaching and educating people to a certain extent, and it is the spiritual force to support its successful long-term development [24].

Before the class, learn to inspire students to learn independently. The class is based on cloud technology, great wisdom, and other information technologies, and the tablet is used to combine the classroom with resources, to provide students with rich learning resources, and to use big data and other technologies for students. The learning process and learning feedback are tracked and evaluated in real time [25]. "Smart classroom" integrates self-learning before class, answering questions and key explanations in the class, and feedback services after class through self-learning plans, microvideos, teaching resources, homework, assessments, etc. "Smart classroom" makes teaching more and more intelligent, makes the education environment more and more networked, and makes students' learning more and more personalized, so that students can adapt to the informationized social environment and promote the development of students' wisdom [26].

The basic teaching process based on the smart classroom is shown in Figure 2. Before class, the teacher analyzes the students' homework, makes clear the students' existing knowledge and experience, and combines the characteristics of the students' age and physical and mental development to preliminarily determine the teaching objectives. According to the learning situation, textbook analysis, teaching difficulties, and problems encountered by students in the preview, teachers determine the teaching design scheme [27]. Students show their own preview results and put forward their own confusion. In the process of inquiry, teachers should give corresponding guidance. The teacher sends the homework to the student client, and the students submit it to the teacher after completing the homework. The teacher corrects the homework in time, gives feedback to the students, and answers questions online through the tablet. Students summarize what they have learned and upload their feelings or questions after class to the learning platform, and teachers organize students to discuss and exchange as an expanding supplement. Teachers push network resources to enable students to expand their learning according to their own situation [28, 29].

\section{Smart Classroom System Simulation Experiment}

3.1. Test Environment of the System. The test environment of the smart classroom teaching system mainly includes the hardware environment and related operating system and the database of the Internet of Things engineering experiment platform constructed with the optical wireless switch and its distributed wireless system as the core, supplemented by the intelligent access gateway and its distributed wired system. The software environment is composed of two parts, and the specific test environment configuration is shown in Table 2.

3.2. Environmental Intelligence Perception. For temperature detection, we mainly use the DS18B20 chip to detect the 


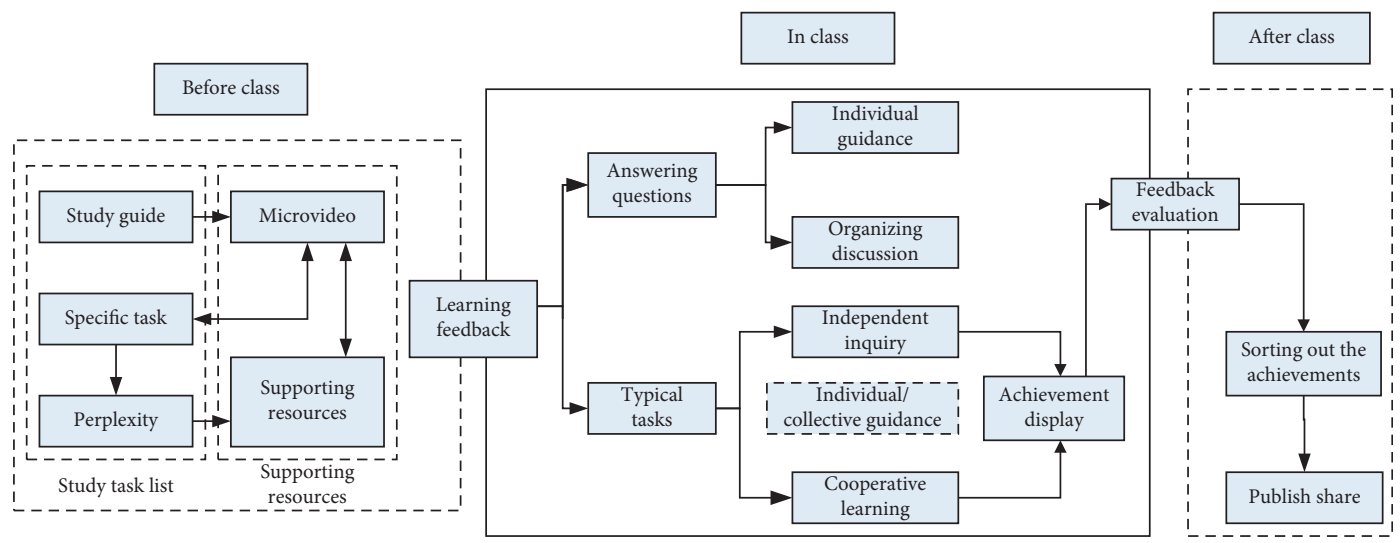

FIgURE 2: The basic teaching process is based on a smart classroom.

TABLE 2: Test environment configuration.

\begin{tabular}{lc}
\hline Name & System and version \\
\hline Web application server & Cent OS 6.0 \\
Web application language & Java \\
Web server middleware & Apache + Jboss + Jdk1.5 \\
Database server & My SQL \\
Front communication server & UNIX \\
Flow media services & Windows Media Services 9 \\
Workstation & Windows ${ }^{\circledR} 7$ Professional 32-bit \\
Optical carrier wireless switch & WCS2410C \\
\hline
\end{tabular}

temperature in the classroom. For the light intensity of the classroom, we use a photoresistor to collect the light data, and after amplification by the amplifier, the A/D sampling process of the single-chip microcomputer is used to obtain the light intensity, combined with the clock module to distinguish the influence of the classroom light. In the classrooms of colleges and universities, most of the participants in the activities are adults, who emit heat and humidity to the outside world. The effective monitoring range is set to $0-100 \mathrm{RH}$, and the resolution is $2.5 \% \mathrm{RH}$. At the same time, the fault self-check and alarm are carried out according to the electrical and physical characteristics of the equipment. In order not to affect the indoor activities or the teaching process, the alarm only occurs on the server side or the user's mobile terminal and does not support the on-site whistle alarm, to facilitate the maintenance and safety of personnel after failure and support human body static electricity or leakage protection.

3.3. Data Acquisition Test. The test adopts the method of observing the source data directly, and the data format is not converted twice, which ensures the accuracy of the source data. The data in the data frame is decoded by relevant software, and the decoded data is printed on the PC screen by means of printf reset. This test uses a USR-TCP232 network debugging assistant to debug the data acquisition. Through the control function of the collected data, we can see that the prototype system of the smart classroom has realized the closed-loop functions such as data acquisition, output and data processing, and equipment control and realized the automatic control. The tester can control the operation of the equipment in real time, and the test function can completely realize the management of the smart classroom, save labor cost, and improve safety index and equipment utilization.

\subsection{Equipment Out-of-Control Alarm Test. After receiving} the control instruction, the control system node starts the regulation of the device. When the device starts to work, it returns information to the host computer management system. The main page device control module will receive the return value of the control device, indicating that the device is in accordance with the configuration, if you do not receive the returned task signal and the system defaults to the device failure or communication failure, then the system will send the control command again. If the execution control command is sent 10 times in a row, the system still has no return signal. Then the system will send the data reported to the mobile phone information reserved by the administrator to report the loss of control of the equipment in the classroom. This enables the administrator to grasp the control and operating status of the equipment in the smart classroom for the first time and to grasp and troubleshoot the faults in time.

3.5. Performance Test. To optimize the safety and reliability of the system, dual-computer backup switching is adopted on the hardware, and process monitoring and management strategies are adopted on the software. The smart classroom teaching system has relatively high requirements for the stable operation of the system, and the data in the system requires long-term storage characteristics, and no accidents are allowed. Once data is lost or the system is paralyzed, it will bring immeasurable consequences to the school. At the same time, the amount of data interaction in the smart classroom is relatively large, so it is necessary to build a highly available cluster server, so that the system not only has a certain degree of stability, but also can quickly respond to users' access requests. 
3.6. Wisdom Evaluation. This study uses the intelligent evaluation method to evaluate the quality of teaching and learning. In the intelligent evaluation, the intelligent teaching tool rain classroom collects the data of students' learning process or learning results to realize the comprehensive evaluation of students. The big data provides an important support for the evaluation of smart classroom teaching. According to various data sources, modular analysis technology is used to form visual analysis results. The former teaching evaluation is a single evaluation by teachers. In the intelligent evaluation, teachers are the main body of students' evaluation, students are the objects being evaluated and the main body of evaluation and the evaluation of teaching and learning quality.

\section{Results and Discussion}

The actual space layout of the smart classroom is shown in Figure 3. With the support of cloud desktop, mobile Internet, and other technologies, it has formed a smart classroom cloud desktop software, a smart classroom cloud desktop management system, a smart classroom cloud desktop computing module, a smart classroom cloud desktop storage module, and a live lesson anchor system (the teaching environment background system (teaching platform) and the smart classroom cloud desktop terminal). On the equipment, learners and teachers clearly stated that the current hardware equipment needs to be upgraded and reformed, and they believe that the number, location, size, and clarity of the display screens need to be reconsidered, the mutual interaction of the screens, and the support for handheld devices and audio systems should be "silent" and can support the interaction between teachers and students. The quality of the network continues to be strengthened, and the diversity of the physical environment needs to be strengthened. In addition, it is hoped that a lighter or green version of learning tools can be provided, and the type and quantity of various terminal equipment consider it.

The benefits of the smart classroom model to students in all aspects are shown in Table 3 . It can be seen from the table that $76.9 \%$ of the students think this teaching method is very helpful to improve their interest in learning, and $23.1 \%$ of the students think it is helpful, which fully shows that everyone has fully recognized that this teaching method can improve their interest in learning. In terms of improving intercultural communication ability, $61.5 \%$ of the students think it is very helpful, $23.1 \%$ think it is helpful, and $15.4 \%$ hold a neutral attitude. Most of the students think this teaching method is helpful for them to improve their intercultural communication ability.

The smart classroom teaching system uses more teachers and students, so when the maximum number of users is online, the average response time of system transactions is required to be less than 5 seconds, the maximum response time is less than 10 seconds, and the response transaction success rate is higher than $98 \%$, and the CPU is occupied. The rate should be less than $80 \%$, and the memory usage should be less than $80 \%$. The specific test data is shown in Table 4 . When the load of the number of online users reaches 500 , the average response time of the system is 3.65 seconds,

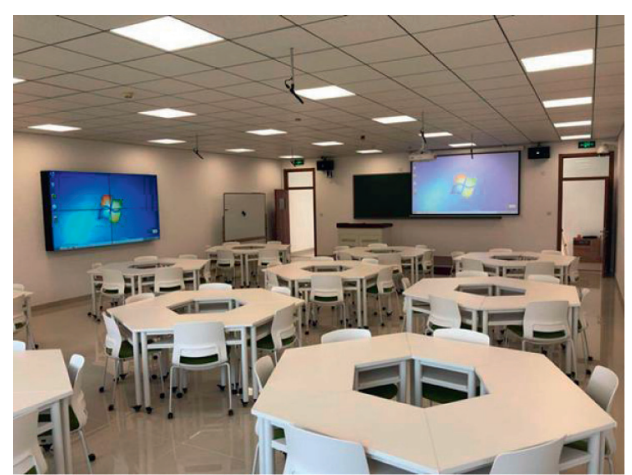

FIgUre 3: The actual layout of the smart classroom (picture from http://alturl.com/dxjfb).

and the maximum response time is 5.11 seconds, which is in line with the expected value. The CPU and memory occupancy rate can also ensure the stability of the system.

To evaluate the effectiveness of the smart classroom model, this article selects 100 high school students in parallel classes to ensure that they have no obvious differences in all aspects except for the different teaching models. The comparison result of classroom teaching structure is shown in Figure 4. In this experimental study, the interactive behavior of the experimental class with students as the main body accounted for $50 \%$, which was higher than the proportion of the interactive behavior with the teacher as the main body (46.7\%); the interactive behavior of the control class with the student as the main body accounted for $40.6 \%$, lower than the proportion of interactive behavior with teachers as the main body (57.9\%). Compared with the two classes, the proportion of interactive behavior with students as the main body in the experimental class is about $10 \%$ higher than that in the control class, and the proportion of interactive behavior with teachers as the main body is about $11 \%$ lower than that in the control class.

The experimental environment chosen in this paper is an indoor test environment, with a distance of five meters between the terminal node and the coordinator, and there is no obstruction in the line of sight. Operate according to the above process and observe the final result. After power-on, we use an oscilloscope to observe the data transmission waveform diagram of the data transceiver interface. The figure shows the level signal of the chip data pin during the data transmission and reception process. The high level represents the number 1, the low level represents the number 0 , and the waveform diagram shows the chip can receive the data sent. The waveform diagram is shown in Figure 5 . According to the test results, the coordinator successfully obtained the data packets transmitted from the device terminal. The content of the data packet was verified to prove that the content of the data packet was consistent before and after the data transmission, and no data transmission errors were found. According to the comparison of the difference between the sent data timestamp and the received data timestamp in the data packet header, we can calculate that the average transmission time is about $10 \mathrm{~ms}$ and $99.9 \%$ of the data transmission delay is less than $30 \mathrm{~ms}$. 
TABLE 3: The benefits of the smart classroom model to students in all aspects.

\begin{tabular}{|c|c|c|c|c|c|}
\hline Survey item & Very helpful & Helpful & General & Not much help & No help \\
\hline Increase interest in learning & $\begin{array}{c}10 \\
76.9 \%\end{array}$ & $\begin{array}{c}3 \\
23.1 \%\end{array}$ & $\begin{array}{c}0 \\
0.0 \%\end{array}$ & $\begin{array}{c}0 \\
0.0 \%\end{array}$ & $\begin{array}{c}0 \\
0.0 \%\end{array}$ \\
\hline Cultivate learning ability & $\begin{array}{c}6 \\
46.1 \%\end{array}$ & $\begin{array}{c}4 \\
30.8 \% \\
\end{array}$ & $\begin{array}{c}2 \\
15.4 \%\end{array}$ & $\begin{array}{c}1 \\
7.6 \%\end{array}$ & $\begin{array}{c}0 \\
0.0 \%\end{array}$ \\
\hline Improve classroom learning enthusiasm & $\begin{array}{c}8 \\
61.5 \%\end{array}$ & $\begin{array}{c}4 \\
30.8 \%\end{array}$ & $\begin{array}{c}1 \\
7.6 \%\end{array}$ & $\begin{array}{c}0 \\
0.0 \%\end{array}$ & $\begin{array}{c}0 \\
0.0 \%\end{array}$ \\
\hline $\begin{array}{l}\text { Improve cross-cultural communication skills } \\
\text { Survey item }\end{array}$ & $\begin{array}{c}8 \\
61.5 \%\end{array}$ & $\begin{array}{c}3 \\
23.1 \%\end{array}$ & $\begin{array}{c}2 \\
15.4 \%\end{array}$ & $\begin{array}{c}0 \\
0.0 \%\end{array}$ & $\begin{array}{c}0 \\
0.0 \%\end{array}$ \\
\hline
\end{tabular}

TABle 4: System test data.

\begin{tabular}{lccccc}
\hline $\begin{array}{l}\text { User } \\
\text { number }\end{array}$ & CPU(\%) & RAM(\%) & $\begin{array}{c}\text { Average response time } \\
\text { (seconds) }\end{array}$ & $\begin{array}{c}\text { Maximum response time } \\
\text { (seconds) }\end{array}$ & $\begin{array}{c}\text { Transaction response success rate } \\
(\%)\end{array}$ \\
\hline 100 & 10 & 8 & 0.85 & 1.77 & 100 \\
200 & 19.5 & 16 & 2.05 & 2.94 & 100 \\
300 & 35.2 & 25 & 2.65 & 3.82 & 100 \\
400 & 47.9 & 37 & 3.15 & 4.73 & 100 \\
500 & 70.4 & 48 & 3.65 & 5.11 & 100 \\
\hline
\end{tabular}

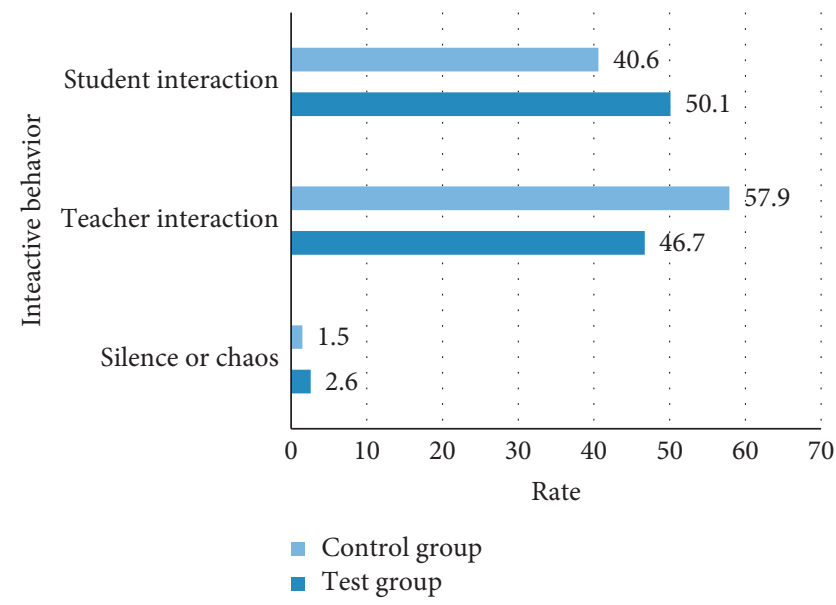

Figure 4: Comparison results of classroom teaching structure.

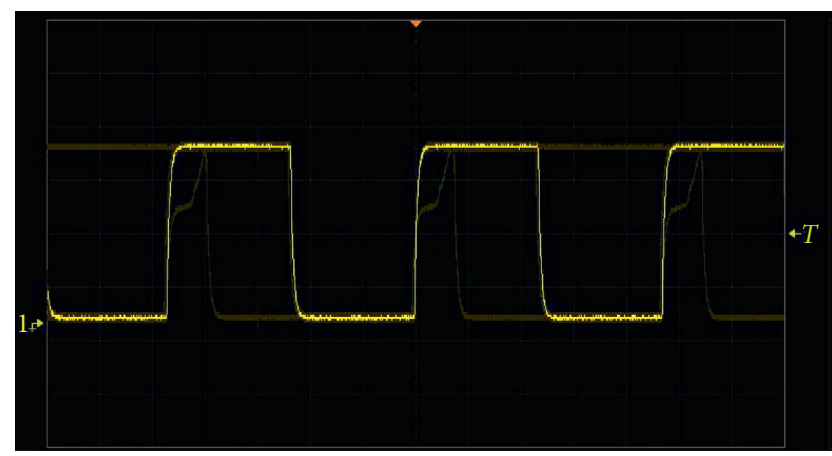

FIGURE 5: Waveform diagram (picture from http://alturl.com/ et6y6).

The system write rate results are shown in Figure 6. As the distance increases, the read and write rates are maintained above $90 \%$, and the trend is generally stable. In the traditional teaching model, teachers impart knowledge to

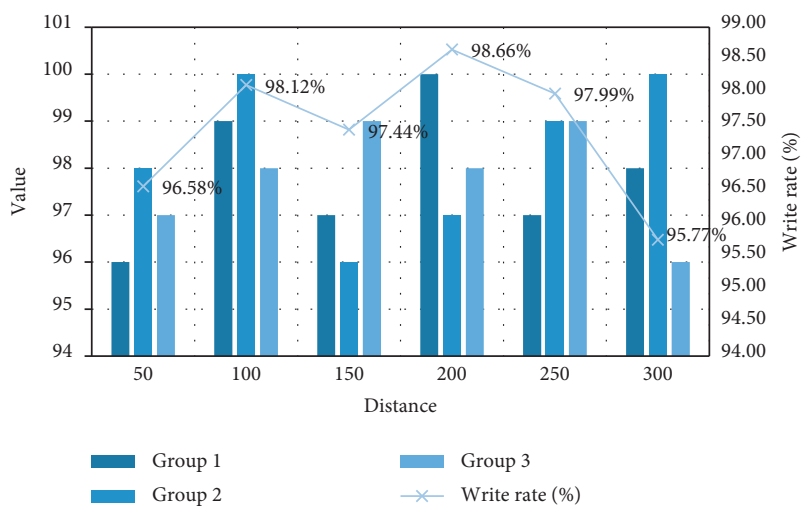

FIGURE 6: System write rate results.

students through books and blackboards, while students test their own learning effects through classrooms and exams, but this traditional model has a single and relatively boring way of imparting knowledge and skills in the classroom. The teaching effect is not good enough and the teacher cannot grasp the students' learning of knowledge and skills in time. The smart classroom is fully adapted to the development of the Internet of Things era, integrating network electronics and practical teaching, enriching teaching methods, and recording the various situations of teachers and students at school through data, and it is also convenient for teachers to understand the students' mastery in a timely manner.

\section{Conclusions}

Educational reforms rely increasing on educational equipment. Only with the help of existing technology can no longer meet the needs of teachers and students, prompting researchers in the field of education to actively and actively develop new technologies and research new educational equipment. New technologies and new equipment account 
for an increasing proportion of smart classrooms, which have become a powerful driving force for the development of smart classrooms. This article tries to find the common problems in the application of teaching informatization by investigating the current status of education informatization construction, to start from the realistic requirements of the operation of the teaching business process and the future innovative teaching business process from the perspective of development needs, the design and implementation of the smart classroom teaching system are discussed and studied. Based on the prototype architecture, implementation strategy and software platform of the Internet of Things application system, this paper presents the implementation plan of the college smart classroom Internet of Things system from the aspects of system realization, main technology, system function realization, and system installation and debugging. The combination of networking application technology and data mining technology, through the application of software platforms, hardware platform, and integrated technologies, solves many information technology problems in classroom management, student attendance, equipment management, and teaching activity management in college education and teaching management.

\section{Data Availability}

No data were used to support this study.

\section{Conflicts of Interest}

The authors declare that they have no conflicts of interest.

\section{Acknowledgments}

This work was supported by General program of Humanities and social sciences of Ministry of Education (No. 18YJCZH084). Key Projects of Dalian Academy of Social Sciences (No. 2020dlsky193).

\section{References}

[1] W. Li, "Design of smart campus management system based on internet of things technology," Journal of Intelligent \& Fuzzy Systems, vol. 40, no. 2, pp. 3159-3168, 2021.

[2] P. W. Kim, "Ambient intelligence in a smart classroom for assessing students' engagement levels," Journal of Ambient Intelligence and Humanized Computing, vol. 10, no. 10, pp. 3847-3852, 2019.

[3] M. Tissenbaum and J. D. Slotta, "Developing a smart classroom infrastructure to support real-time student collaboration and inquiry: a 4-year design study," Instructional Science, vol. 47, no. 1, pp. 1-40, 2019.

[4] Y.-T. Lin, "Impacts of a flipped classroom with a smart learning diagnosis system on students' learning performance, perception, and problem solving ability in a software engineering course," Computers in Human Behavior, vol. 95, pp. 187-196, 2019.

[5] N. Gnotthivongsa, A. K. N. Huangdongjun, A. Huangdongjun, and K. Non Alinsavath, "Real-time corresponding and safety system to monitor home appliances based on the internet of things technology," International Journal of Modern Education and Computer Science, vol. 12, no. 2, pp. 1-9, 2020.

[6] Z. Lv, X. Li, H. Lv, and W. Xiu, "BIM big data storage in WebVRGIS," IEEE Transactions on Industrial Informatics, vol. 16, no. 4, pp. 2566-2573, 2019.

[7] H. Tao, W. Zhao, R. Liu, and M. Kadoch, "Space-air-ground iot network and related key technologies," IEEE Wireless Communications, vol. 27, no. 2, 2019.

[8] R. Atiqur, "Automated smart car parking system for smart cities demand employs internet of things technology," International Journal of Informatics and Communication Technology (IJ-ICT), vol. 10, no. 1, pp. 46-53, 2021.

[9] X. Bai, Q. Wang, and S. Cao, "Application of infusion control system based on internet of things technology in joint orthopedics nursing work," Journal of Healthcare Engineering, vol. 2021, no. 4, pp. 1-11, 2021.

[10] L. Chamba-Eras, A. Gomez, and J. Aguilar, "Multi-agent systems for the management of resources and activities in a smart classroom," IEEE Latin America Transactions, vol. 19, no. 9, pp. 1511-1519, 2021.

[11] J. Aguilar, J. Altamiranda, and F. Diaz, "Specification of a managing agent of emergent serious games for a smart classroom," IEEE Latin America Transactions, vol. 18, no. 1, pp. 51-58, 2020.

[12] Y. Huda and D. Faiza, "Desain sistem pembelajaran jarak jauh berbasis smart classroom menggunakan layanan live video webcasting," Jurnal Teknologi Informasi Dan Pendidikan, vol. 12, no. 1, pp. 25-32, 2019.

[13] Z. Lv and H. Song, "Mobile internet of things under data physical fusion technology," IEEE Internet of Things Journal, vol. 7, no. 5, 2019.

[14] J. Shu, Z. Min, M. Zhi, and Q. Hu, "Research of the university teaching interaction behavior characteristics in the smart classroom," International Journal of Information and Education Technology, vol. 8, no. 11, pp. 773-778, 2018.

[15] M. Miraoui, "A context-aware smart classroom for enhanced learning environment," International Journal on Smart Sensing and Intelligent Systems, vol. 11, no. 1, pp. 1-8, 2018.

[16] S. K. Gupta, T. S. Ashwin, and R. M. R. Guddeti, "Students' affective content analysis in smart classroom environment using deep learning techniques," Multimedia Tools and Applications, vol. 78, no. 18, pp. 25321-25348, 2019.

[17] K. A. Dweikat and H. A. Hasan, "Attitudes of EFL teachers towards using smartphones in the classroom during COVID19 Pandemic," Universal Journal of Educational Research, vol. 9, no. 1, pp. 116-128, 2021.

[18] T. Mailewa, P. Chandrasiri, and D. Chandrasena, "The impact of smart classrooms on the academic success of Sri Lankan government school students," International Journal of Scientific \& Technology Research, vol. 9, no. 12, pp. 323-333, 2020.

[19] M. Djordjević, B. Jovičić, S. Marković, V. Paunović, and D. Danković, "A smart data logger system based on sensor and Internet of Things technology as part of the smart faculty," Journal of Ambient Intelligence and Smart Environments, vol. 12, no. 1, pp. 1-15, 2020.

[20] G. P. Revathi and S. Supreetha, "Smart farm monitoring using internet of things and lora technology based on wireless sensor networks," Journal of Computational and Theoretical Nanoscience, vol. 17, no. 9, pp. 4136-4140, 2020.

[21] A. Mohamed, Q. Peng, and M. M. Abid, "Integrated maintenance logistics monitoring system for high speed rail, based 
on internet of things technology," European Transport \Trasporti Europei, vol. 2020, no. 75-6, pp. 1-10, 2020.

[22] N. Sun, T. Li, G. Song, and H. Xia, "Network security technology of intelligent information terminal based on mobile internet of things," Mobile Information Systems, vol. 2021, no. 8, pp. 1-9, 2021.

[23] Z. Ark, "The effect of "internet of things" technology in the digital transformation process of businesses letmelerin dijital dnüüm sürecinde "nesnelerin interneti" teknolojisinin etkisi," Turkish Studies - Economics Finance Politics, vol. 15, no. 3, pp. 1247-1266, 2020.

[24] C. Civelek, "Evaluation of internet of things (IoT) technology to be used as a precision agriculture solution for Turkey's agriculture," Fresenius Environmental Bulletin, vol. 29, no. 7A, pp. 5689-5695, 2020.

[25] A. Mohammadian, J. H. Dahooie, and A. R. Qorbani, "Identifying and categorizing data analytics applications of internet of things (IoT) technology in the field of smart agriculture by using meta synthesis method (in Persian)," SRELS Journal of Information Management, vol. 6, no. 1, pp. 1-23, 2020.

[26] S. Xu, J. Chen, M. Wu, and C. Zhao, "E-commerce supply chain process optimization based on whole-process sharing of internet of things identification technology," Computer Modeling in Engineering \& Sciences, vol. 126, no. 2, pp. 843-854, 2021.

[27] X. Kong, Y. Xu, Z. Jiao, D. Dong, X. Yuan, and S. Li, "Fault location technology for power system based on information about the power internet of things," IEEE Transactions on Industrial Informatics, vol. 16, no. 10, pp. 6682-6692, 2020.

[28] L. Zhang, H. Yuan, and S. H. Chang, "Research on the overall architecture of internet of things middleware for intelligent industrial parks," The International Journal of Advanced Manufacturing Technology, vol. 107, no. 3, pp. 1081-1089, 2020.

[29] A. Ghosh, S. Liaquat, and S. Ahmed, "Healthcare-internet of things (H-IoT) can assist and address emerging challenges in healthcare," International Journal of Innovative Science \& Technology, vol. 1, no. 2, pp. 12-18, 2021. 